\title{
Prevalence of Nontuberculous Mycobacterial Pulmonary Disease, Germany, 2009-2014
}

\author{
Felix C. Ringshausen, Dirk Wagner, \\ Andrés de Roux, Roland Diel, David Hohmann, \\ Lennart Hickstein, Tobias Welte, \\ Jessica Rademacher
}

We analyzed routine statutory health insurance claim data to determine prevalence of nontuberculous mycobacterial pulmonary disease in Germany. Documented prevalence rates of this nonnotifiable disease increased from 2.3 to 3.3 cases/100,000 population from 2009 to 2014 . Prevalence showed a strong association with advanced age and chronic obstructive pulmonary disease.

$\mathrm{N}$ ontuberculous mycobacteria (NTM) are a biologically diverse group of microorganisms that may cause progressive NTM pulmonary disease (NTM-PD), particularly in persons who have risk factors such as advanced age or chronic airway diseases (1-3). However, populationbased data on the epidemiology of NTM-PD are scarce, particularly in Europe. We used hospital discharge codes from the International Classification of Diseases, 10th revision (ICD-10), as a surrogate to demonstrate that NTMPD prevalence is steadily increasing in Germany, as is the case in many other countries (4-6). However, we assumed that most patients with this chronic infection are managed in outpatient care. The objective of this population-based study was to estimate the annual overall prevalence rates of NTM-PD in Germany over a 6-year period and to analyze the distribution of age and sex, the site of healthcare provision, and concomitant conditions, using a representative sample of routine statutory health insurance claims data.

\section{The Study}

This study was based on the population of Germany of $\approx 81$ million during 2009-2014, and a subgroup of $\approx 70$ million persons $(86 \%)$ covered by German statutory

Author affiliations: German Center for Lung Research, Giessen, Germany (F.C. Ringshausen, R. Diel, T. Welte); Hannover Medical School, Hannover, Germany (F.C. Ringshausen, T. Welte, J. Rademacher); University Hospital Freiburg, Freiburg, Germany (D. Wagner); Pneumologische Praxis am Schloss Charlottenburg, Berlin, Germany (A. de Roux); University Medical Center Schleswig-Holstein, Kiel, Germany (R. Diel); HGC GesundheitsConsult, Düsseldorf, Germany (D. Hohmann); Health Risk Institute, Berlin (L. Hickstein)

DOI: http://dx.doi.org/10.3201/eid2206.151642 health insurance (Table 1) (7). Because this study was based on anonymous routine data, institutional review board approval and patient consent were not required. We obtained anonymous health claims data from the Health Risk Institute health services research database, which contains a subset of $\approx 7$ million persons covered by statutory health insurance. This database has been validated and shows good overall accuracy in documenting the German population in terms of illness, death, and drug usage; in addition, the number of insured persons in the database remains high over time $(8)$. We established data characteristics by adjustments for age and sex according to the distribution within the general population of Germany (7). Only persons who were continuously insured within the respective year were considered. Of those persons, we obtained a 5\% sample representative of the German population for each year of the study period, consisting of $\approx 4$ million persons per year (Table 1). From these samples, we extracted records that used the ICD-10 diagnosis code A31.0 (NTM-PD) for either a primary or a secondary diagnosis, and we analyzed data according to age, sex, the site of healthcare provision (Table 1), and the most common and relevant associated conditions, as represented by concomitantly recorded ICD-10 codes (Table 2).

We calculated rates, 95\% CI, and differences between means using OpenEpi version 3.03a as previously described (9). Statistical significance was set to $p<0.05$. Accordingly, differences were considered insignificant if $95 \%$ CIs were overlapping. We obtained official census data from the German Federal Statistical Office (7).

During 2009-2014, we identified 85-126 case-patients with NTM-PD per year; distribution of sex was balanced (Table 1). Mean age was not significantly different between male and female patients except for in 2013, when the female patient ages were higher than those of the male patients $(p=0.038)$. Most $(76 \%-87 \%)$ case-patients were treated in outpatient settings (Table 1). The most frequent concomitant diagnoses throughout the study period were chronic obstructive pulmonary disease and emphysema (COPD/emphysema [ICD-10 codes J43-J44]) in 62\%$79 \%$ of the case-patients (Table 2).

During 2009-2014, the annual overall prevalence rate increased from 2.3 (95\% CI 1.87-2.87) to 3.3 (95\% CI $2.78-3.94$ ) per 100,000 population (Figure 1), and the corresponding projected total number of case-patients with NTM-PD in Germany increased from 1,907 to 2,697. Overall, annual rates did not differ substantively between 
Table 1. Prevelance of nontuberculous mycobacterial pulmonary disease, stratified by age, sex, and year; Germany, 2009-2014*

\begin{tabular}{|c|c|c|c|c|c|c|}
\hline Characteristic & 2009 & 2010 & 2011 & 2012 & 2013 & 2014 \\
\hline Population of Germany, total- no. & $81,802,257$ & $81,751,602$ & $80,327,900$ & $80,523,746$ & $80,767,463$ & $81,197,537$ \\
\hline Mean age, y & 43.4 & 43.7 & 43.9 & 44.1 & 44.2 & 44.3 \\
\hline Sex ratio, F:M & 1.04 & 1.04 & 1.05 & 1.05 & 1.04 & 1.04 \\
\hline $\begin{array}{l}\text { No. persons insured by SHI (\% Germany } \\
\text { population) }\end{array}$ & $\begin{array}{l}70,011,718 \\
(85.6)\end{array}$ & $\begin{array}{l}69,803,236 \\
(85.4)\end{array}$ & $\begin{array}{l}69,637,277 \\
(86.7)\end{array}$ & $\begin{array}{l}69,704,323 \\
\quad(86.6)\end{array}$ & $\begin{array}{l}69,861,165 \\
(86.5)\end{array}$ & $\begin{array}{l}70,289,808 \\
\quad(86.6)\end{array}$ \\
\hline $\begin{array}{l}\text { No. persons in study sample (\% Germany } \\
\text { population) }\end{array}$ & $\begin{array}{l}3,646,060 \\
(4.5)\end{array}$ & $\begin{array}{l}3,708,501 \\
(4.5)\end{array}$ & $\begin{array}{l}3,985,981 \\
(5.0)\end{array}$ & $\begin{array}{l}3,982,716 \\
(4.9)\end{array}$ & $\begin{array}{l}3,977,676 \\
(4.9)\end{array}$ & $\begin{array}{l}3,793,331 \\
(4.7)\end{array}$ \\
\hline Mean age, y & 44.0 & 44.1 & 43.7 & 44.0 & 44.3 & 45.1 \\
\hline Sex ratio, F:M & 1.03 & 1.03 & 1.04 & 1.04 & 1.04 & 1.04 \\
\hline No. case-patients with NTM-PD & 85 & 96 & 106 & 106 & 104 & 126 \\
\hline M, no. (\% case-patients with NTM-PD) & $43(50.6)$ & $50(52.1)$ & $50(47.2)$ & $60(56.6)$ & $49(47.1)$ & $63(50.0)$ \\
\hline F, no. (\% case-patients with NTM-PD) & $42(49.4)$ & 46 (47.9) & $56(52.8)$ & $46(43.4)$ & $55(52.9)$ & $63(50.0)$ \\
\hline Outpatient care, no. (\% case-patients & $74(87.1)$ & 79 (82.3) & $80(75.5)$ & $88(83.0)$ & $85(81.7)$ & $104(82.5)$ \\
\hline with NTM-PD) & & & & & & \\
\hline $\begin{array}{l}\text { Hospital care, no. (\% case-patients with } \\
\text { NTM-PD) }\end{array}$ & $20(23.5)$ & $28(29.2)$ & $34(32.1)$ & $25(23.6)$ & $37(35.6)$ & $38(30.2)$ \\
\hline Outpatient and hospital care, no. (\% & $9(10.6)$ & $11(11.5)$ & $8(7.5)$ & $7(6.6)$ & $18(17.3)$ & $16(12.7)$ \\
\hline Case-patients with NTM-PD) & & & & & & \\
\hline $\begin{array}{l}\text { Hospital but no outpatient care in the } \\
\text { same year, no. (\% case-patients who had } \\
\text { hospital care) }\end{array}$ & $11(55.8)$ & $17(60.7)$ & $26(76.5)$ & $18(72.0)$ & $19(51.4)$ & $22(57.9)$ \\
\hline $\begin{array}{l}\text { Mean age of case-patients with NTM-PD, y } \\
\text { (SD) }\end{array}$ & $60.3(20.0)$ & $57.3(22.2)$ & $55.0(23.8)$ & $55.5(25.4)$ & $59.7(22.6)$ & $61.0(20.4)$ \\
\hline 皮 & $58.7(20.1) \dagger$ & $55.3(21.3) \dagger$ & $57.6(20.0) \dagger$ & $55.2(25.3) \dagger$ & $54.8(24.6) \ddagger$ & $58.2(19.3) \dagger$ \\
\hline $\mathrm{F}$ & $62.1(20.0)$ & $59.4(23.2)$ & $52.7(26.7)$ & $56.0(25.7)$ & $64.1(19.8)$ & $63.7(21.2)$ \\
\hline $\begin{array}{l}\text { Prevalence, rate } / 100,000 \text { population, total } \\
(95 \% \mathrm{Cl})\end{array}$ & $\begin{array}{l}2.3(1.87- \\
2.87)\end{array}$ & $\begin{array}{l}2.6(2.11- \\
3.15)\end{array}$ & $\begin{array}{l}2.7(2.19- \\
3.20)\end{array}$ & $\begin{array}{l}2.7(2.19- \\
3.21)\end{array}$ & $\begin{array}{l}2.6(2.15- \\
3.16)\end{array}$ & $\begin{array}{l}3.3(2.78- \\
3.94)\end{array}$ \\
\hline $\mathrm{M}$ & $\begin{array}{l}2.4(1.76- \\
3.20)\end{array}$ & $\begin{array}{l}2.8(2.06- \\
3.59)\end{array}$ & $\begin{array}{l}2.6(1.92- \\
3.34)\end{array}$ & $\begin{array}{l}3.1(2.36- \\
3.92)\end{array}$ & $\begin{array}{l}2.5(1.88- \\
3.29)\end{array}$ & $\begin{array}{c}3.4(2.63- \\
\quad 4.31)\end{array}$ \\
\hline $\mathrm{F}$ & $\begin{array}{c}2.3(1.65- \\
3.03)\end{array}$ & $\begin{array}{c}2.4(1.81- \\
3.22)\end{array}$ & $\begin{array}{c}2.8(2.10- \\
3.56)\end{array}$ & $\begin{array}{c}2.3(1.68- \\
3.0)\end{array}$ & $\begin{array}{c}2.7(2.07- \\
3.51)\end{array}$ & $\begin{array}{c}3.3(2.53- \\
4.14)\end{array}$ \\
\hline Projected total number of case-patients & 1,907 & 2,116 & 2,136 & 2,143 & 2,112 & 2,697 \\
\hline
\end{tabular}

${ }^{*} \mathrm{SHI}$, statutory health insurance; NTM-PD, nontuberculous mycobacterial pulmonary disease.

†Mean age was not significantly different among male and female patients: $2009, p=0.44 ; 2010, p=0.37 ; 2011, p=0.28 ; 2012, p=0.87 ; 2014, p=0.13$. $\ddagger \mathrm{p}=0.038$ for mean age between male and female patients.

male and female patients (Table 1). We observed the highest prevalence rates among case-patients $\geq 50$ years of age, in particular among those $\geq 80$ years of age in 2014 (9.4 [95\% CI 4.35-17.78] cases/100,000 population for men and 9.6 [95\% CI 5.44-15.65] cases/100,000 population for women; Figure 2).

\section{Conclusions}

We found an increasing annual prevalence rate of NTMPD in Germany during 2009-2014, from 2.3 to 3.3 cases/100,000 population. These rates are consistent with the average annual hospitalization rate of 0.9/100,000 population observed for 2005-2011 (6) but are considerably lower than the rate of $6.5 / 100,000$ population that was recently estimated for Germany by an expert panel by using a 2-round Delphi consensus-building method (10). A study in the United States documented an overall prevalence of 5.5 cases $/ 100,000$ person-years and a prevalence rate of 27 and 57/100,000 population among case-patients $\geq 60$ and $\geq 80$ years of age, respectively, during 2004-2006 (4). This rate is $\approx 5$ times higher than our findings of 6.5 and 9.5/100,000 population among the same age groups in Germany during 2014. In contrast to the US study, which found that NTM-PD was more frequent among women, we found no substantive differences concerning annual overall prevalence rates related to sex.

Several implications arise from our findings. Our analysis suggests that NTM-PD remains a rare disease in Germany, with a prevalence rate below the European cutoff of 5 cases/10,000 population (11) and less than half the prevalence of tuberculosis $(\approx 2,700$ versus 6,300 prevalent cases in 2014) (12). Furthermore, in agreement with recent data from the United States (5), we found that chronic airway diseases (e.g., COPD/emphysema and bronchiectasis) were present in most case-patients diagnosed with NTMPD $(\leq 79 \%$ and $\leq 18 \%$, respectively). Hence, case-patients with these diseases, in particular those on long-term and high-dose inhaled corticosteroid therapy (13), should be considered for NTM-PD screening.

The data we collected indicate that most NTM-PD illness in Germany is managed in outpatient care (Table 1). In addition, our data show that a substantial proportion of case-patients had acute conditions (influenza and pneumonia, $\leq 34 \%$ ) when concomitantly diagnosed with NTM-PD. We surmise that these case-patients are at risk for not being monitored for NTM-PD because $>50 \%$ of them did not 
Table 2. Most common and relevant comorbidities among case-patients with nontuberculous mycobacterial pulmonary disease, Germany, 2009-2014*

\begin{tabular}{|c|c|c|c|c|c|c|c|}
\hline \multirow[b]{2}{*}{ ICD-10 codes } & \multirow[b]{2}{*}{ Diagnosis } & \multicolumn{6}{|c|}{ No. (\%) patients } \\
\hline & & 2009 & 2010 & 2011 & 2012 & 2013 & 2014 \\
\hline A31.0 & NTM-PD & 85 & 96 & 106 & 106 & 104 & 126 \\
\hline $\mathrm{J} 43-44$ & COPD and emphysema & $53(62.4)$ & $67(69.8)$ & $84(79.2)$ & $67(63.2)$ & $76(73.1)$ & $87(69.0)$ \\
\hline $\mathrm{J} 40-42$ & Chronic or unspecified bronchitis & $24(28.2)$ & $26(27.1)$ & $34(32.1)$ & $28(26.4)$ & $44(42.3)$ & $41(32.5)$ \\
\hline E10-11 & Diabetes mellitus, type 1 and type 2 & $45(52.9)$ & $28(29.2)$ & $15(14.2)$ & 20 (18.9) & $21(20.2)$ & $28(22.2)$ \\
\hline J09-18 & Influenza and pneumonia & $21(24.7)$ & $17(17.7)$ & $28(26.4)$ & $24(22.6)$ & 35 (33.7) & $29(23.0)$ \\
\hline M80-81 & Osteoporosis & $18(21.2)$ & $20(20.8)$ & $27(25.5)$ & $23(21.7)$ & $23(22.1)$ & $26(20.6)$ \\
\hline J45 & Asthma & $18(21.2)$ & $25(26.0)$ & $31(29.2)$ & $22(20.8)$ & $23(22.1)$ & $34(27.0)$ \\
\hline J96 & Respiratory failure & $16(18.8)$ & $21(21.9)$ & $25(23.6)$ & 20 (18.9) & $23(22.1)$ & $33(26.2)$ \\
\hline J20-22 & Acute bronchitis and bronchiolitis & $8(9.4)$ & $17(17.7)$ & $17(16.0)$ & $27(25.5)$ & $18(17.3)$ & $26(20.6)$ \\
\hline A15-19 & Tuberculosis & $12(14.1)$ & $14(14.6)$ & $16(15.1)$ & $21(19.8)$ & $25(24.0)$ & $17(13.5)$ \\
\hline F17 & Tobacco use & $13(15.3)$ & $17(17.7)$ & $17(16.0)$ & $16(15.1)$ & $14(13.5)$ & $16(12.7)$ \\
\hline K21 & Gastro-esophageal reflux disease & $13(15.3)$ & $15(15.6)$ & $18(17.0)$ & $14(13.2)$ & $17(16.3)$ & $20(15.9)$ \\
\hline J47 & Bronchiectasis & $6(7.1)$ & $9(9.4)$ & $9(8.5)$ & $7(6.6)$ & $16(15.4)$ & $23(18.3)$ \\
\hline C34 & Lung cancer & $3(3.5)$ & $4(4.2)$ & $7(6.6)$ & $9(8.5)$ & $5(4.8)$ & $13(10.3)$ \\
\hline M05-06 & Rheumatoid arthritis & $3(3.5)$ & $11(11.5)$ & $8(7.5)$ & $4(3.8)$ & $2(1.9)$ & $9(7.1)$ \\
\hline B20-24 & Human immunodeficiency virus & $1(1.2)$ & $2(2.1)$ & $5(4.7)$ & $4(3.8)$ & $5(4.8)$ & $5(4.0)$ \\
\hline D90 & Immunosuppression & 0 & $1(1.0)$ & $2(1.9)$ & $1(0.9)$ & $2(1.9)$ & $1(0.8)$ \\
\hline Z94 & Transplant organ and tissue status & $1(1.2)$ & $1(1.0)$ & $1(0.9)$ & 0 & $2(1.9)$ & $2(1.6)$ \\
\hline E84 & Cystic fibrosis & 0 & $1(1.0)$ & 0 & 0 & $2(1.9)$ & $2(1.6)$ \\
\hline
\end{tabular}

*ICD-10, International Classification of Diseases, 10th revision; NTM-PD, nontuberculous mycobacterial pulmonary disease; COPD, chronic obstructive pulmonary disease.

return as outpatients with the diagnosis of NTM-PD in the same year (Table 1). If this is the case, this finding emphasizes the need for continuing medical education on NTMPD to increase clinical awareness.

Our study has limitations. First, the annual overall numbers of samples from case-patients in this study in which NTM-PD was diagnosed were low. Second, our findings are based on ICD-10 diagnosis codes and therefore are likely to underestimate the overall prevalence of NTM-PD, in particular when considering the low percentage of case-patients receiving American Thoracic Society/Infectious Diseases Society of America guidelinecompliant treatment for NTM-PD (14). ICD-10 codes are primarily intended for reimbursement purposes; they lack validation for NTM-PD within the healthcare system of Germany and have unknown sensitivity and specificity

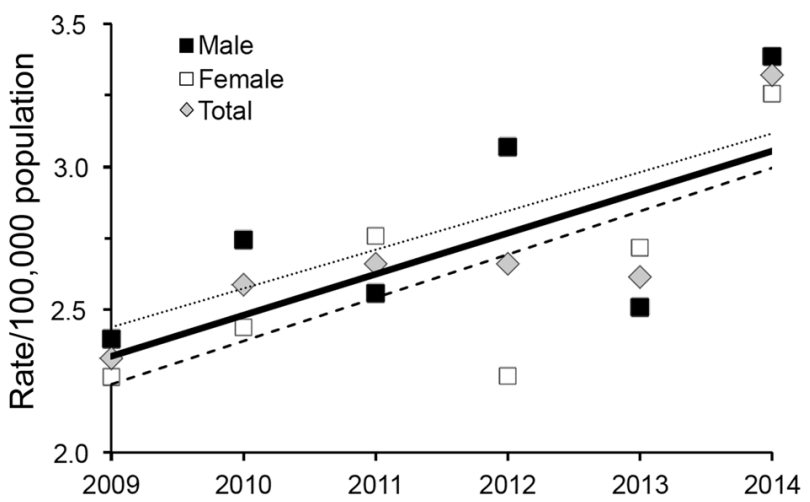

Figure 1. Trends in annual prevalence of nontuberculous mycobacterial pulmonary disease by sex and year, Germany, 2009-2014. Solid trend line indicates overall prevalence; dotted linear trend line, male prevelance; dashed linear trend line, female prevalence. for the use of the ICD-10 diagnostic code for NTM-PD. Moreover, assignment of ICD-10 codes does not require compliance with the American Thoracic Society/Infectious Diseases Society of America diagnostic criteria for NTM-PD (1), and the codes do not provide details on isolated mycobacterial species. Last, we were unable to account for regional differences across Germany. The eastern parts of Germany are slightly underrepresented in the Health Risk Institute database (8); therefore, our findings may not fully apply to all regions, and they may not fully apply to cohorts outside the German statutory health insurance system.

In conclusion, the annual prevalence rate of NTM-PD and, accordingly, the projected total number of cases in Germany increased during 2009-2014. Increased clinical awareness and additional reliable data on the epidemiology of NTM-PD are urgently needed, in particular with respect to COPD/emphysema. These goals could be met if NTMPD were a notifiable disease or comprehensive diseasespecific registries were established (15).

F.C. Ringshausen, R. Diel, and T. Welte are members of the German Center for Lung Research (DZL).

This study was supported in part by a grant from Insmed Germany, Frankfurt, Germany, provided to Dr. Ringshausen. However, Insmed Germany had no influence on acquisition, adjustment, analysis, and interpretation of data. Dr. Ringshausen has received prior grants and research as well as editorial support from Insmed Germany. In addition, Dr. Ringshausen, Dr. de Roux, Prof. Diel, Prof. Welte, and Dr. Rademacher have received personal fees from Insmed Germany for consultancy and lectures. 


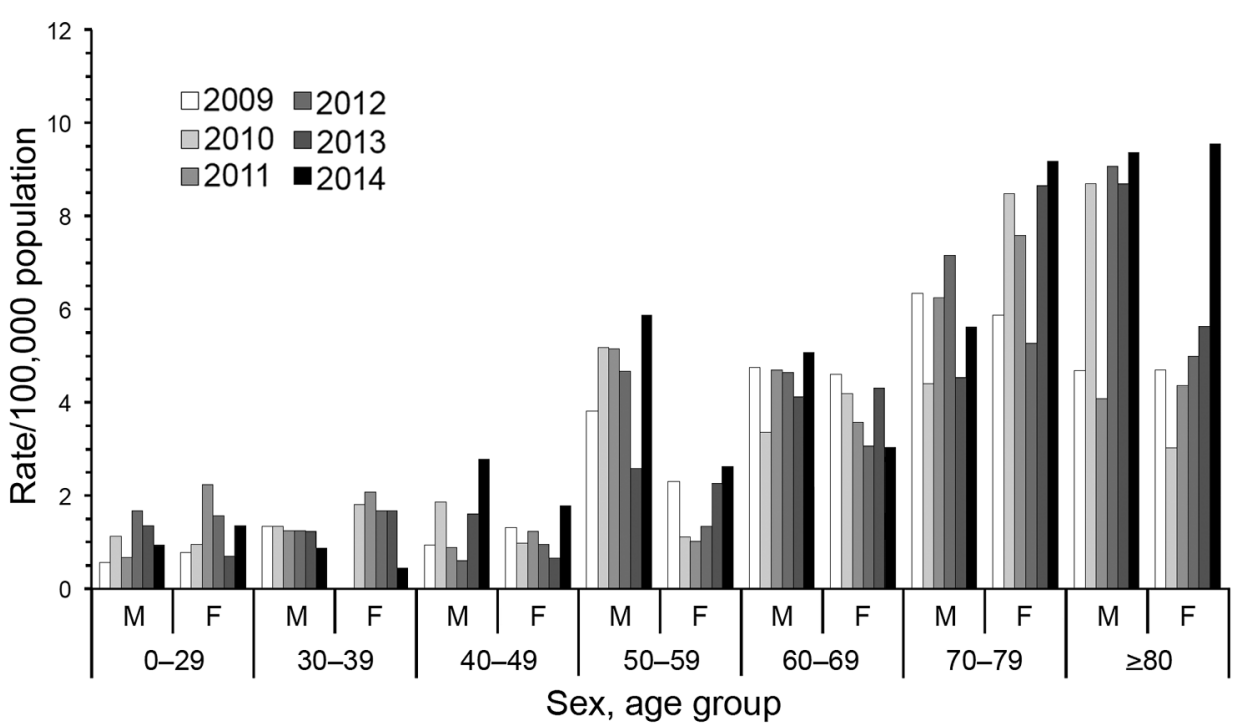

Figure 2. Prevalence rates of nontuberculous mycobacterial pulmonary disease, by age group, sex, and year, Germany, 2009-2014.

Dr. Ringshausen is attending physician, head of the Respiratory Infections and Adult Cystic Fibrosis Service of the Hannover Medical School in Hannover, Germany, and a pulmonary physician with specialization in infectious diseases. His research interests include respiratory infections, with emphasis on bronchiectasis, nontuberculous mycobacterial infections, tuberculosis, and adult cystic fibrosis.

\section{References}

1. Griffith DE, Aksamit T, Brown-Elliott BA, Catanzaro A, Daley C, Gordin F, et al. An official ATS/IDSA statement: diagnosis, treatment, and prevention of nontuberculous mycobacterial diseases. Am J Respir Crit Care Med. 2007;175:367-416. http://dx.doi.org/10.1164/rccm.200604-571ST

2. Thomson RM. Changing epidemiology of pulmonary nontuberculous mycobacteria infections. Emerg Infect Dis. 2010;16:1576-83. http://dx.doi.org/10.3201/eid1610.091201

3. Hoefsloot W, van Ingen J, Andrejak C, Angeby K, Bauriaud R, Bemer $\mathrm{P}$, et al. The geographic diversity of nontuberculous mycobacteria isolated from pulmonary samples: an NTM-NET collaborative study. Eur Respir J. 2013;42:1604-13. http://dx.doi.org/10.1183/09031936.00149212

4. Prevots DR, Shaw PA, Strickland D, Jackson LA, Raebel MA, Blosky MA, et al. Nontuberculous mycobacterial lung disease prevalence at four integrated health care delivery systems. Am J Respir Crit Care Med. 2010;182:970-6. http://dx.doi.org/ 10.1164/rccm.201002-0310OC

5. Adjemian J, Olivier KN, Seitz AE, Holland SM, Prevots DR. Prevalence of nontuberculous mycobacterial lung disease in U.S. Medicare beneficiaries. Am J Respir Crit Care Med. 2012;185: 881-6. http://dx.doi.org/10.1164/rccm.201111-2016OC

6. Ringshausen FC, Apel RM, Bange FC, de Roux A, Pletz MW, Rademacher J, et al. Burden and trends of hospitalisations associated with pulmonary non-tuberculous mycobacterial infections in Germany, 2005-2011. BMC Infect Dis. 2013;13:231. http://dx.doi.org/10.1186/1471-2334-13-231
7. German Federal Statistical Office. Facts \& figures-state \& societyFederal Statistical Office (Destatis). 2015 Sep 19 [cited 2015 Sep 19]. http://www.destatis.de/EN/FactsFigures/SocietyState/ SocietyState.html

8. Andersohn F, Walker J. Characteristics and external validity of the German Health Risk Institute (HRI) Database. Pharmacoepidemiol Drug Saf. 2016;25:106-9. http://dx.doi.org/10.1002/pds.3895

9. Dean AG, Sullivan KM, Soe MM, Mir RA. OpenEpi: Open source epidemiologic statistics for public health, version 3.03a. 2015 May 4 [cited 2015 Sept 19]. http://www.OpenEpi.com

10. Wagner D, van Ingen J, Adjemian J, Lange C, Prevots DR, Griffith D, et al. Annual Prevalence and Treatment Estimates for Nontuberculous Mycobacterial Pulmonary Disease in Europe: A NTM-NET Collaborative Study. Eur Respir J. 2014;44(Suppl 58):1067. http://erj.ersjournals.com/content/44/Suppl_58/P1067

11. European Commission. Policy-European Commission. 2016 [cited 2016 Feb 21]. http://ec.europa.eu/health/rare_diseases/ policy/index_en.htm

12. World Health Organization. Global Health Observatory Data Repository. 2015 [cited 2016 Feb 21]. http://apps.who.int/ghodata/

13. Andréjak C, Nielsen R, Thomsen VO, Duhaut P, Sorensen HT, Thomsen RW. Chronic respiratory disease, inhaled corticosteroids and risk of non-tuberculous mycobacteriosis. Thorax. 2013;68: 256-62. http://dx.doi.org/10.1136/thoraxjnl-2012-201772

14. van Ingen J, Adjemian J, Morimoto K, Wagner D, Lange C, Haworth $\mathrm{C}$, et al. Comparison of treatment practices for nontuberculous mycobacterial pulmonary disease in Japan, Europe, and the United States. Eur Respir J. 2014;44 (Suppl 58):1066.

15. Aksamit TR, Carretta E, Daley CL, O'Donnell AE, Thomashow B, Dominik R, et al. The Bronchiectasis Research Registry: a collaborative research cohort for non-cystic fibrosis bronchiectasis [abstract]. Am J Respir Crit Care Med. 2012;185:A3654.

Address for correspondence: Felix C. Ringshausen, Department of Respiratory Medicine, Hannover Medical School, Carl-Neuberg-Strasse 1, 30625 Hannover, Germany; email: Ringshausen.Felix@mh-hannover.de 